\title{
Inhalation Toxicity of Ethylene Glycol in Rat
}

\section{Hyun-Mi Kim*, Jung-Taek Kwon, II-Seob Shim, Do-Young Kwon, Yeon-Mi Lim, Eun-Ji Kim, Pil-Je Kim and Kyunghee Choi}

Risk Assessment Division, Department of Environmental Health Research, National Institute of Environmental Research, Hwangyong-ro, 42, Incheon, 404-708, The Republic of Korea

"Corresponding author: Hyun-Mi Kim, Risk Assessment Division, Department of Environmental Health Research, National Institute of Environmental Research, Hwangyong-ro, 42, Incheon, 404-708, The Republic of Korea, Tel: +82-32-560-7169; Fax: +82-32-568-2037; E-mail: hmikim@korea.kr

Rec date: Dec 09, 2015; Acc date: Jan 25, 2016; Pub date: Jan 27, 2016

Copyright: $\odot 2016 \mathrm{Kim} \mathrm{HM}$, et al. This is an open-access article distributed under the terms of the Creative Commons Attribution License, which permits unrestricted use, distribution, and reproduction in any medium, provided the original author and source are credited.

\begin{abstract}
Several air fresheners and deodorants that contain ethylene glycol were found $(1-2 \%(\mathrm{w} / \mathrm{v}))$ in commercially available products. Ethylene glycol is a liquid used as a surfactant or an emulsifier in household products. The aim of this study is to determine the inhalation toxicity of ethylene glycol. The effect of whole-body inhalation to EG was performed for an inhalation study of rat. Specific pathogen-free male Sprague-Dawley rats (7 weeks old) were exposed to ethylene glycol in a stainless steel whole body inhalation chamber with a capacity of $1 \mathrm{~m}^{3}$ (Sibata Model VT3-X15 Japan). For acute and sub-acute rat inhalation toxicities, the differences of body weights were not statistically significant comparing with those of control rats. In sub-acute rat inhalation toxicity, the relative kidney weights were significantly higher in high-exposure group $\left(500 \mathrm{mg} / \mathrm{m}^{3}\right)$ than those of the other groups. In blood biochemistry the values of TG (triglyceride) and BUN (urea nitrogen) were significantly decreased. Other hematological changes with toxicological relevance were not observed in exposed male rats when compared with the control animals. The histopathological findings were not observed in the lung and kidney tissues exposed to chemicals comparing with those of control tissues. The No Observed Adverse Effect Level (NOAEL) of EG in 28 day's inhalation test was evaluated to be over $100 \mathrm{mg} / \mathrm{m}^{3}$.
\end{abstract}

Keywords: Inhalation toxicity; Ethylene glycol; MTT assay; BAL fluid; LDH; TP

\section{Introduction}

Various chemicals are used in household products including disinfectants, deodorants, air fresheners, paints, cosmetics and hair sprays. In particular, spray-form household products, generating respirable particles in the air, can be the major source of inhalation exposure of chemicals during daily activities [1-4]. A variety of products used in our daily lives contain substances of unknown hazards which may cause chemical safety issues [5]. As seen in the incident of humidifier disinfectant in 2011, chemicals contained in consumer products could have high risk of inhalation toxicity while showing a low level of general toxicity [6-7]. However, inhalation toxicity tests are limitedly conducted because of their high cost and time-consuming aspects. Several air fresheners and deodorants that contain ethylene glycol were found $(1-2 \%(w / v))$ in commercially available products. Ethylene glycol is a liquid used as a surfactant, an emulsifier or anti-freezing agent [8]. Ethylene glycol can induce severe kidney toxicity when ingested in large amount [9]. Ethylene glycol is a polyhydric alcohol solvent being a clear, sweat tasting, viscous and odourless liquid [10]. Eighty percent of absorbed ethylene glycol is metabolized in the liver by alcohol dehydrogenase to several acid metabolites (glycolic acid, glyoxilic acid, oxalic acid) which are responsible for high anion gap metabolic acidosis, calcium oxalate crystals and renal injury [11-13]. Eventhough there exist toxic effects in ingestion exposure, ethylene glycol might not to be toxic for intratrachial instillation in our previous study [14]. Our previous study showed that intratracheal instillation of ethylene glycol (100 and 200 $\mu \mathrm{g} / \mathrm{kg}$ ) did not induce any changes in body weight compared with the control rats. And singly treated ethylene glycol did not induce any changes in LDH activity and protein content in BALF of lung at 1 and $7 \mathrm{~d}$ after exposure in rats. Therefore, the purpose of this study is to conduct the in vivo rat whole body inhalation toxicity of ethylene glycol (EG) as dominant substance used in air fresheners and deodorants.

\section{Materials and Methods}

\section{Animals and exposure conditions}

Specific pathogen-free male Sprague-Dawley rats (7 weeks old) were purchased from Orient Bio Inc. (Korea) and acclimated for 1 week before the experiments. The rats were housed under standard laboratory conditions $\left(22 \pm 3^{\circ} \mathrm{C}\right.$ temperature, $50 \pm 20 \%$ humidity, $12 \mathrm{hr}$ day/night cycles, $12 \sim 15$ air changes per hour). The rats were housed singlely in stainless steel wire mesh cages and allowed to access to hepa filtered tap water and commercial rodent chow (DIET 5L79, PMI nutrition LLC). Ethylene glycol was supplied from Sigma Co. and test solutions were prepared by diluting with distilled water. Then the ethylene glycol solutions were aerosolized using a mist generator (NB-2N Sibata Japan) with $25 \mathrm{~L} / \mathrm{min}$ of air flow. The aerosol generating system was directly connected to a stainless steel whole body inhalation exposure chamber with a capacity of $1 \mathrm{~m}^{3}$ (Sibata Model VT3-X15 Japan). The concentrations of ethylene glycol aerosol in chambers were measured by collecting samples of each chamber with Sampler and by using the weight difference filter (T60A20, Ф55) before and after filtering. For size distribution of ethylene glycol, flow of $2 \mathrm{~L} / \mathrm{min}$ was collected for $20 \mathrm{~min}$ using Anderson sampler and the weight of filters (T60A20, Ф55) were measured by each phases of filtering. In acute inhalation toxicity, body weights were measured at the beginning of the study, $1^{\text {st }}$ day, $3^{\text {rd }}$ day, $7^{\text {th }}$ day and $14^{\text {th }}$ day after exposure and the exposure termination day. In subacute inhalation 
Page 2 of 5

toxicity (28 day), body weights were measured at the beginning of the study, at twice weekly intervals during the exposure and at exposure termination. Ethylene glycol aerosols were sampled three times during every six hour exposure period through a sampling line using glass fiber filters. Particle size distribution in aerosol was measured using a small-size cascade impactor. Temperature, relative humidity, pressure and air ventillation in the chambers were recorded using an environmental controller.

\section{Blood analysis}

Blood samples of the animals were drawn from the ventral aorta by using a syringe under anesthesia. The blood samples were collected into CBC bottles containing EDTA (K2 EDTA, BD vacutainer) and were analyzed within 15 min using a Hemavet automatic hematology analyzer(Drew Scientific, Dallas, Texas, USA). The following parameters were determined: white blood cell(WBC), neutrophil(NE), lymphocyte(LY), monocyte(MO), eosinophil(EO), basophil(BA), red blood cell(RBC), platelet(PLT), hemoglobin(Hb), hematocrit(HCT), mean corpuscular hemoglobin $(\mathrm{MCH})$, mean corpuscular hemoglobin concentration(MCHC), red blood cell distribution width(RDW), mean corpuscular volume(MCV) and mean plasma volume(MPV). Blood samples were drawn from the ventral aorta using a syringe and collected in a serum vacutainer. The sera were collected by centrifugation at 3,000 rpm for $10 \mathrm{~min}$ within $2 \mathrm{hr}$ after collection and stored at $-80^{\circ} \mathrm{C}$ in a freezer prior to analysis. The following serum biochemistry parameters were determined using an automatic serum analyzer(Drichem4000, Fuji Photo Film, Japan): alkaline phosphatase(ALP), lactate dehydrogenase(LDH), glucose(GLU), total cholesterol(TCHO), glutamic oxaloacetate transaminase(GOT), glutamic pyruvate transaminase(GPT), urea nitrogen in blood (BUN), calcium(Ca), inorganic phosphorus(IP), gamma glutamyl transferase(GGT), albumin(ALB), total protein(TP), creatinine(CRE), total bilirubin(TBIL), sodium $(\mathrm{Na})$, potassium $(\mathrm{K})$ and chlorine $(\mathrm{Cl})$.

\section{Histopathological analysis}

After the 4 week inhalation of ethylene glycol, the animals were sacrificed under the anesthesia with isoflurane, and lungs, kidneys, livers, hearts, spleens and thymus were excised. The excised organs were weighed and the relative organ weight was calculated with division of organ weights by body weights and reported as $\mathrm{mg} / 100 \mathrm{~g}$ body weight. Clinical observation was performed on animals during exposure and post-exposure, including appearance, mobility, hemorrhage and abnormal breath once a day during the experiment. The right lobes of the lungs and kidneys were fixed in $10 \%$ neutral buffered formalin for 7 days. After routine tissue processing, the tissues were embedded in paraffin, and the sections $(2-3 \mu \mathrm{m})$ were prepared on the glass slide. The tissue sections were stained with hematoxylin and eosin (H \& E) and examined under the light microscope (Olympus DP70, Tyoko, Japan). The lesions were separately graded depending on severity by pathologists.

\section{Statistical analysis}

Statistical analyses were performed using SPSS version 12 with nonparametric statistical test for ethylene glycol exposed and control groups. Values were expressed as the mean \pm standard deviation (S.D.) of 5 animals. Differences at $\mathrm{p}<0.05$ were considered statistically significant by the test. A multiple variance of analysis (ANOVA) test and student's t-test (Graphpad Software, CA USA) were used to compare exposure groups with a control group.

\section{Results and Discussion}

The groups of five male rats were exposed to ethylene glycol $(0,20$, $100,500 \mathrm{mg} / \mathrm{m}^{3}$ ) for 4 hours/day in acute inhalation toxicity. The measured concentrations of ethylene glycol were $(17.3 \pm 1.51) \mathrm{mg} / \mathrm{m}^{3}$, $(62.9 \pm 7.26) \mathrm{mg} / \mathrm{m}^{3},(576.3 \pm 54.74) \mathrm{mg} / \mathrm{m}^{3}$ (Table 1). Groups of five male rats were exposed to ethylene glycol $\left(0,4,20,100 \mathrm{mg} / \mathrm{m}^{3}\right)$ for sub-acute inhalation toxicity ( 28 day study). The measured concentrations of ethylene glycol were $(4.14 \pm 0.42) \mathrm{mg} / \mathrm{m} 3,(21.67 \pm$ $2.51) \mathrm{mg} / \mathrm{m}^{3}$, $(103.07 \pm 9.19) \mathrm{mg} / \mathrm{m}^{3}$ (Table 2). To allow for exposure of all relevant regions of the respiratory tract, aerosols with mass median aerodynamic diameter (MMAD) values ranging from 1 to $3 \mu \mathrm{m}$ with a geometric standard deviation in the range of 1.5 to 3.0 are recommended [15]. The mass median aerodynamic diameter (MMAD) values were between 2.34 and $5.78 \mu \mathrm{m}$ (Table 3) and those values are matched with the OECD Guideline for Testing of Chemicals No.412.

\begin{tabular}{|l|l|l|l|}
\hline \multirow{2}{*}{ Groups } & \multicolumn{3}{l|}{ Concentration $\left(\mathbf{m g} / \mathbf{m}^{3}\right)$} \\
\cline { 2 - 4 } & Mean & $\min$ & $\max$ \\
\hline Low $\left(20 \mathrm{mg} / \mathrm{m}^{3}\right)$ & $17.3 \pm 1.51$ & 15.6 & 18.4 \\
\hline Middle $\left(100 \mathrm{mg} / \mathrm{m}^{3}\right)$ & $62.9 \pm 7.26$ & 55.2 & 69.6 \\
\hline High $\left(500 \mathrm{mg} / \mathrm{m}^{3}\right)$ & $576.3 \pm 54.74$ & 514.4 & 618.4 \\
\hline
\end{tabular}

Table 1: The concentration of ethylene glycol during acute inhalation exposure.

\begin{tabular}{|l|l|l|l|}
\hline \multirow{2}{*}{ Groups } & \multicolumn{3}{|l|}{ Concentration $\left(\mathrm{mg} / \mathrm{m}^{3}\right)$} \\
\cline { 2 - 4 } & Mean & $\min$ & $\max$ \\
\hline Low $\left(4 \mathrm{mg} / \mathrm{m}^{3}\right)$ & $4.14 \pm 0.42$ & 3.6 & 4.8 \\
\hline Middle $\left(20 \mathrm{mg} / \mathrm{m}^{3}\right)$ & $21.67 \pm 2.51$ & 18.4 & 23.6 \\
\hline High $\left(100 \mathrm{mg} / \mathrm{m}^{3}\right)$ & $103.07 \pm 9.19$ & 87.7 & 117.6 \\
\hline
\end{tabular}

Table 2: The concentration of ethylene glycol during subacute inhalation exposure.

\begin{tabular}{|l|l|}
\hline Exposure group & MMAD $(\boldsymbol{\mu m})$ \\
\hline Low $\left(4 \mathrm{mg} / \mathrm{m}^{3}\right)$ & 2.34 \\
\hline Middle $\left(20 \mathrm{mg} / \mathrm{m}^{3}\right)$ & 6.66 \\
\hline High $\left(100 \mathrm{mg} / \mathrm{m}^{3}\right)$ & 5.78 \\
\hline
\end{tabular}

Table 3: The MMAD of ethylene glycol during subacute inhalation exposure.

No treatment-related adverse symptoms such as mobility, abnormalities of breathing, bleeding or mortality were observed in any of rats inhaled with ethylene glycol during the acute and sub-acute experiment period. The LC50 (inhalation, $4 \mathrm{hr}$, rat) of ethylene glycol might be estimated higher than $500 \mathrm{mg} / \mathrm{m} 3$ because there are no mortality in highest concentration chamber $\left(500 \mathrm{mg} / \mathrm{m}^{3}\right)$. In acute inhalation toxicity, body weights were measured at the beginning of the study, $1^{\text {st }}$ day, $3^{\text {rd }}$ day and $7^{\text {th }}$ day after exposure and the exposure termination day. No significant body weight changes when compared 
with control were observed in acute toxicity of ethylene glycol treated groups (Figure 1).

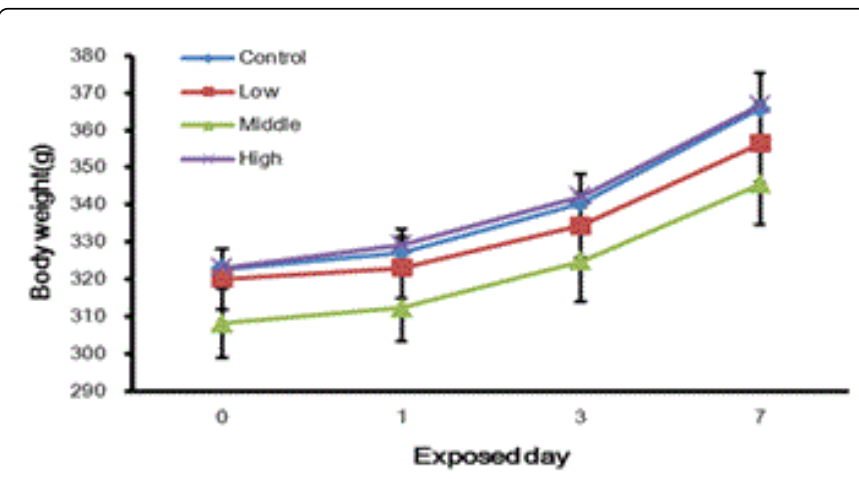

Figure 1: Changes of body weight in SD rats after 4-hour inhalation of ethylene glycol. The groups of five male rats were exposed to ethylene glycol $\left(0,20,100,500 \mathrm{mg} / \mathrm{m}^{3}\right)$ for 4 hours/day in acute inhalation toxicity. In acute inhalation toxicity, body weights were measured at the beginning of the study, $1^{\text {st }}$ day, $3^{\text {rd }}$ day and $7^{\text {th }}$ day after exposure and the exposure termination day. Low: $20 \mathrm{mg} / \mathrm{m}^{3}$, middle: $100 \mathrm{mg} / \mathrm{m}^{3}$, high: $500 \mathrm{mg} / \mathrm{m}^{3}$.

In sub-acute inhalation toxicity, body weights were measured every day after exposure and the exposure termination day. No significant body weight changes when compared with control were observed in male ethylene glycol treatment groups (Figure 2). The relative kidney weights (right and left) were significantly increased compared with those in the control group (Figure 3).

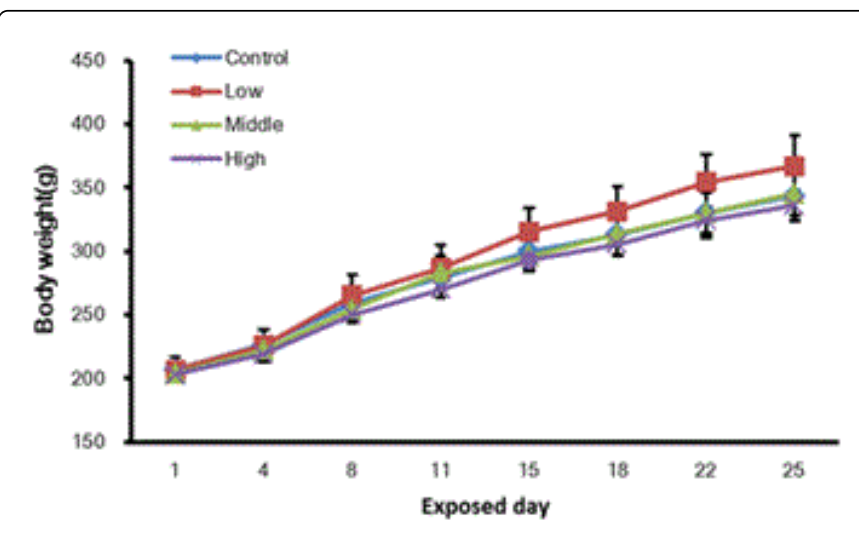

Figure 2: Changes of body weight in SD rats after 28 days inhalation of ethylene glycol. The groups of five male rats were exposed to ethylene glycol $\left(0,4,20,100 \mathrm{mg} / \mathrm{m}^{3}\right)$ for sub-acute inhalation toxicity ( 28 day study). Low: $4 \mathrm{mg} / \mathrm{m}^{3}$, middle: $20 \mathrm{mg} / \mathrm{m}^{3}$, high: 100 $\mathrm{mg} / \mathrm{m}^{3}$.

Blood samples were taken from all surviving rats before necropsy in acute toxicity. No significant differences were apparant between the control and treatment groups for any clinical chemistry parameters such as WBC, RBC and lymphocyte examined. Biochemical changes with toxicological relevance were not found in ethylene glycol exposed male rats when compared with control animals. The sub-acute toxicity results of the hematology tests on male rats are shown that the white blood cell levels significantly decreases in all ethylene glycol exposed groups. No significant differences between control and treatment groups were apparent, especially for red blood cell, lymphocyte and hemoglobin. The levels of triglyceraldehyde were significantly decreased compared with those with ethylene glycol treated group. The other biochemical serum levels such as total cholesterol and glutamic pyruvic transaminase were no difference between control and ethylene glycol treatment groups.

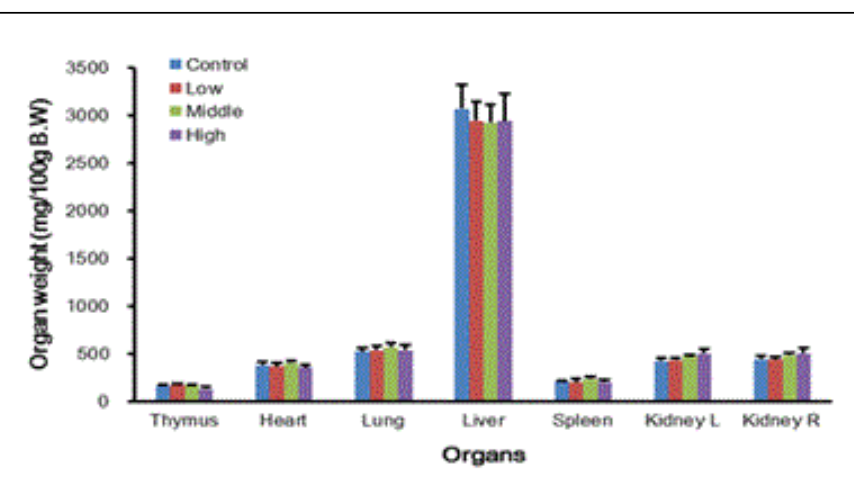

Figure 3: Relative organ weight of SD rats after 28 days inhalation of ethylene glycol. The groups of five male rats were exposed to ethylene glycol $\left(0,4,20,100 \mathrm{mg} / \mathrm{m}^{3}\right)$ for subacute inhalation toxicity ( 28 day study). Low: $4 \mathrm{mg} / \mathrm{m}^{3}$, middle: $20 \mathrm{mg} / \mathrm{m}^{3}$, high: 100 $\mathrm{mg} / \mathrm{m}^{3}$.

The sub-acute toxicity results of the histopathological examinations are shown in Table 4. Histopathological changes were not observed in the lungs and kidneys in the ethylene glycol treatment groups (Table 4 and Figure 4). Among five control group rats, right kidney local nephropathy was observed in two rats and basophilic tubule was observed in one rat of left kidney. Among low exposed group, right kidney local nephropathy was observed in one rat and basophilic tubule was observed in the right kidneys of three rats and the left kidneys of two rats (Figure 5). Tubular dilatation was expanded in right kidney of three rats and left kidney of four rats. The local infiltration of stroma cell was observed in right kidney of one rat. Among middle exposed group, tubular dilatation was expanded in right and left kidney of all five rats and the local infiltration of lymphocyte was observed in the right kidney of one rat. In high exposed group, the local nephropathy was observed in one rat of both right and left kidney. In high exposed group, basophilic tubule observed in right kidney of one rat and left kidney of two rats. Even though several mild lesions were observed such as tubular dilatations in every exposed group, the histopathological results were similar between control and exposed groups.

Through the previous study of intratracheal instillation tests, we investigated the inflammation response of ethylene glycol in BAL Fluid analysis (Inhalation toxicity screening study on chemicals used in consumer products 2013 NIER). The LDH and total Protein levels in BAL Fluid, as markers of cytotoxicity and injury of membrane in the lungs exposed to ethylene glycol were increased significantly in a dosedependent manner. These results were in good agreement with the result of this inhalation toxicity test. Also, the No Observed Adverse Effect level (NOAEL) of Ethylene glycol in 28 days inhalation test was evaluated to be over $100 \mathrm{mg} / \mathrm{m}^{3}$. 
Citation: Kim HM, Kwon JT, Shim S, Kwon DY, Lim YM, et al. (2016) Inhalation Toxicity of Ethylene Glycol in Rat . J Veterinar Sci Technol 7: 292. doi:10.4172/2157-7579.1000292

Page 4 of 5

\begin{tabular}{|c|c|c|c|c|c|c|c|c|}
\hline Histopathology/Group & \multicolumn{2}{|c|}{ Control } & \multicolumn{2}{|l|}{ Low } & \multicolumn{2}{|l|}{ Middle } & \multicolumn{2}{|l|}{ High } \\
\hline \multicolumn{9}{|l|}{ Lung } \\
\hline No. of examined & \multicolumn{2}{|l|}{5} & \multicolumn{2}{|l|}{5} & \multicolumn{2}{|l|}{5} & \multicolumn{2}{|l|}{5} \\
\hline No specific lesion & \multicolumn{2}{|l|}{$5(100)$} & \multicolumn{2}{|c|}{$5(100)$} & \multicolumn{2}{|l|}{$5(100)$} & \multicolumn{2}{|l|}{$5(100)$} \\
\hline Kidney & Rt & $\mathrm{Lt}$ & Rt & $\mathrm{Lt}$ & Rt & $\mathrm{Lt}$ & Rt & $\mathrm{Lt}$ \\
\hline No. of examined & 5 & 5 & 5 & 5 & 5 & 5 & 5 & 5 \\
\hline No specific lesion & $1(20)$ & $1(20)$ & $0(00)$ & $1(20)$ & $1(20)$ & $0(00)$ & $0(00)$ & $1(20)$ \\
\hline local nephropathy & $2(40)$ & $0(00)$ & $1(20)$ & $0(00)$ & $0(00)$ & $0(00)$ & $1(20)$ & $1(20)$ \\
\hline Basophilic tubules, multifocal & $0(00)$ & $1(20)$ & $3(60)$ & $2(40)$ & $0(00)$ & $0(00)$ & $1(20)$ & $2(40)$ \\
\hline Tubular dilatation, diffuse & $3(60)$ & $3(60)$ & $3(60)$ & $4(80)$ & $5(100)$ & $5(100)$ & $5(100)$ & $5(100)$ \\
\hline Lymphocyte infiltration, focal & $0(00)$ & $0(00)$ & $1(20)$ & $0(00)$ & $1(20)$ & $0(00)$ & $0(00)$ & $0(00)$ \\
\hline
\end{tabular}

Table 4: Histopathological findings for lung and kidney of rats after 28 days inhalation of ethylene glycol.

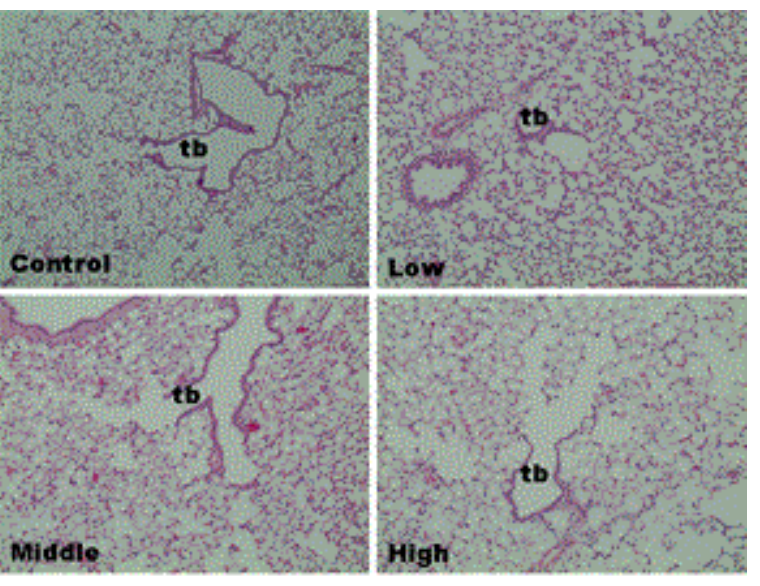

Figure 4: Histopathology of the lung of rat after 28 days inhalation of ethylene glycol. No abnormal findings were observed in all the groups. tb, terminal bronchioles. $\mathrm{H} \& \mathrm{E}$. Mag $=\times 100$ for all the groups of five male rats were exposed to ethylene glycol $(0,4,20$, $100 \mathrm{mg} / \mathrm{m}^{3}$ ) for sub-acute inhalation toxicity (28 day study). Low: 4 $\mathrm{mg} / \mathrm{m}^{3}$, middle: $20 \mathrm{mg} / \mathrm{m}^{3}$, high: $100 \mathrm{mg} / \mathrm{m}^{3}$.

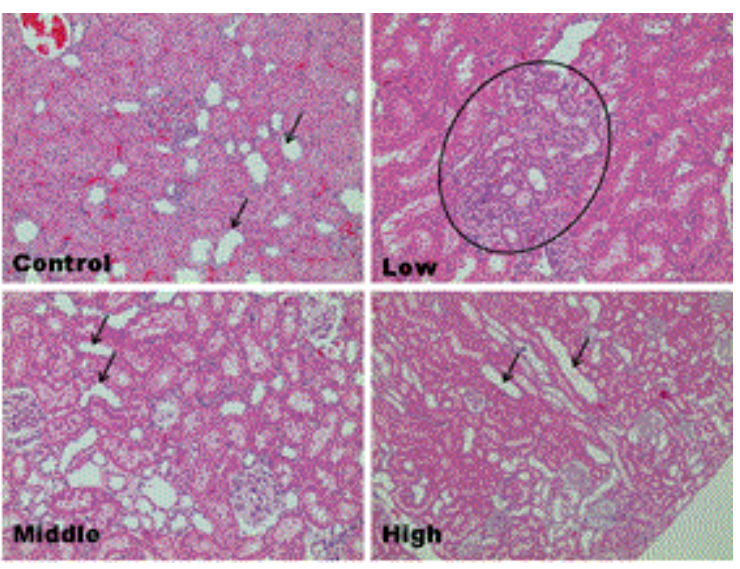

Figure 5: Histopathology of the kidney of rat after 28 days inhalation of ethylene glycol. Note the ditailed distal tubulesin the renal cortex (arrows). Dilatation of proximal tubules was also noted in the middle and the high dose groups. Focal nephropathy was often observed, characterized by basophilic tubules with thickened basement membrane and mild inflammatory cell infiltration (circle). H \& E. Mag $=\times 200$ for control, low and middle group and $\times 100$ for high group. The groups of five male rats were exposed to ethylene glycol $\left(0,4,20,100 \mathrm{mg} / \mathrm{m}^{3}\right)$ for subacute inhalation toxicity ( 28 day study). Low: $4 \mathrm{mg} / \mathrm{m}^{3}$, middle: $20 \mathrm{mg} / \mathrm{m}^{3}$, high: 100 $\mathrm{mg} / \mathrm{m}^{3}$.

\section{Acknowledgements}

This research was supported by the National Institute of Environmental Research (NIER), Republic of Korea.

\section{Conflict of Interest}

The authors declare that there are no conflicts of interest. 
Citation: Kim HM, Kwon JT, Shim S, Kwon DY, Lim YM, et al. (2016) Inhalation Toxicity of Ethylene Glycol in Rat . J Veterinar Sci Technol 7: 292. doi:10.4172/2157-7579.1000292

Page 5 of 5

\section{References}

1. Hahn S, Schneider K, Gartiser S, Heger W, Mangelsdorf I (2010) Consumer exposure to biocides-identification of relevant sources and evaluation of possible health effects. Environ Health 9: 7.

2. Gupta RC (2014) Respiratory toxicity biomarkers. In Biomarkers in Toxicology (1stedn), Academic Press, Waltham pp. 216-239.

3. McClellan RO, Henderson RF (1995) Biological markers in the respiratory tract In: Concepts in inhalation toxicology (2nd Edn), CRC press, Boca Raton, pp. 441-470.

4. Shim I, Seo GB, Oh E, Lee M, Kwon JT, et al. (2013) Inhalation exposure to chloramine $\mathrm{T}$ induces DNA damage and inflammation in lung of Sprague-Dawley rats. J Toxicol Sci 38: 937-946.

5. Park GH, Rhu CJ, Kim YS (2012) Risk assessment for hazardous substances contained in consumer products. National Institute of Environmental Research No. NIER-SP2012-174.

6. Kim HM, Kwon JT, Kwon DY, Kim EJ, Lim YM, et al. (2014) Inhalation toxicity screening study of chemical mixture(I). National Institute of Environmental Research, No. NIER-RP2014-220.

7. Kwon JT, Yang YS, Kang MS, Seo GB, Lee DH, et al. (2013) Pulmonary toxicity screening of triclosan in rats after intratracheal instillation. J Toxicol Sci 38: 471-475.
8. NTP-CERHR (2004) NTP CERHR Monograph on the Potential Human Reproductive and Developmental Effects of Ethylene Glycol. NIH Publication No 04-4481.

9. Porter WH (2012) Ethylene glycol poisoning: quintessential clinical toxicology; analytical conundrum. Clin Chim Acta 413: 365-377.

10. Nagesh IV, Koley KC2, Sen S3, Mohan S4, Sahu S5 (2015) Ethylene glycol poisoning. Med J Armed Forces India 71: S36-S38.

11. Wills JH, Coulston F, Harris ES, McChesney EW, Russell JC, et al. (1974) Inhalation of aerosolized ethylene glycol by man. Clin Toxicol 7: 463-476.

12. Carstens J, Csanády GA, Faller TH, Filser JG (2003) Human inhalation exposure to ethylene glycol. Arch Toxicol 77: 425-432.

13. Upadhyay S, Carstens J, Klein D, Faller TH, Halbach S, et al. (2008) Inhalation and epidermal exposure of volunteers to ethylene glycol: kinetics of absorption, urinary excretion, and metabolism to glycolate and oxalate. Toxicol Lett 178: 131-141.

14. Kwon DY, Kim HM, Kwon JT, Kim EJ, Kim PJ, et al. (2015) Acute pulmonary toxicity and inflammation induced by combined exposure to didecyldimethylammonium chloride and ethylene glycol in rats. Journal of Toxicological Sciences In press.

15. OECD (2009) Subacute Inhalation Toxicity: 28-Day Study. OECD Guideline for Testing of Chemicals No.403. 